beans, and occasional meat, are taken at home. The work could not be kept up day after day if the food were not abundant. We were told that this food is almost entirely the produce of the land the men are irrigating and cultivating. The actual men who work the shadoufs and do the other work on the land are joint farmers. They thus work jointly for themselves and pay the rent jointly, taking all the produce and profits from its sale after the rent has been paid. The rents seem enormous by British or American standards, but the land, as actually worked, is extremely productive. It is very improbable that if the men were working on daily or weekly wages they would work so effectively or obtain the same net earnings. It seems also to be for essentially the same reasons that modern power-driven appliances have not displaced the shadouf. A shadouf is not only extremely efficient mechanically, but can be made from materials on the spot, and can be at any time repaired by the men who use it. To judge from carvings on a tomb near Luxor, the shadouf was practically the same more than three thousand years ago as it is now.

The work done on a shadouf is of special physiological interest, because it is so well standardised, employs so many muscles, and is so easily measured directly. In most kinds of standardised work we can only measure the work indirectly from the oxygen-consumption. In the late Mr. Jervis Smith's book on "Dynamometers" (edited by Prof. Boys) a description is given, on page Io, of another easily measured form of standardised human muscular work. This form of work was employed early last century in raising the earth needed in the construction of forts round Paris. The earth was loaded into a bucket attached to a rope passing over a pulley, and was then drawn up by the action of a counterpoise consisting of a man, whose work consisted in continuously ascending a ladder and coming down as a counterpoise to the ascending earth. It was found that the work done in this way amounted to 4230 foot-pounds per hour-a figure very close to ours for the shadouf worker as regards the rate per hour, though the French navvies kept up this rate during eight hours daily.

There can be no doubt that where the motive is adequate a man in good physical training, and fed in correspondence with the work, can keep up day after day, for say eight hours, a considerably greater rate of measured work than corresponds to these figures; and for short periods far greater rates are possible. Thus Henderson and Haggard (Amer. Journ. of Physio$\log y, 72$, p. 264, 1925) found that over a four-mile race in 22 minutes each oarsman of a university crew did average measured work at a rate of 0.45 . horsepower, or 15,000 foot-pounds a minute, with a total energy-expenditure of 19 calories a minute, or at the rate of II 40 calories per hour. This rate is $3^{\frac{1}{2}}$ times that of the shadouf workers, but, of course, could not be kept up nearly so long. In a $\mathrm{I}_{4}^{1}$ mile rowing race the rate rose to 0.57 horse-power, or 18,770 foot-pounds a minute. For very short periods of less than a minute, still higher rates are possible, even for an untrained man. For example, Douglas and Haldane, with the view of producing maximum discharges of lactic acid from muscles during their temporary lack of oxygen, used short bursts of climbing work at a rate of 30,000 foot-pounds per minute (Journ. of Physiology, 38, p. 43I, I909). The rates of work of the shadouf men and of the French navvies are, however, worthy of record, as these rates could, without unusual effort, be maintained day after day throughout the working period.

We have pleasure in acknowledging the help we received from Mr. George Gattas, of Luxor, a chief dragoman on Messrs. Cook's Nile Service steamers.

\title{
Audibility of Explosions and the Constitution of the Upper Atmosphere.
}

By F. J. W. Whipple.

DHYSICISTS who are interested in the problem of the temperature and constitution of the upper atmosphere have been awaiting with some impatience the publication of the official reports on the audibility of the experimental explosions arranged by the International Commission for Investigations on the Sound of Explosions. The first experiment was made (at Oldebroek in Holland) in October 1922, but the full report on the second experiment or series of experiments has appeared first. This report ${ }^{1}$ has been prepared by Prof. Charles Maurain, head of the Institut de Physique du Globe at Paris. Some idea of the mass of evidence that has been digested may be gathered from the facts that 405 observations were plotted on the map showing the audibility of the first explosion, 360 and 240 on the maps for the second and third.

The site of the explosions was at La Courtine; this place is about half-way between Paris and the Pyrenees ; as it is more than $250 \mathrm{~km}$. from the nearest sea, the audibility in all directions could be investigated. There were four explosions, on May I 5, 23, 25, and 26,

1 Annales de l'Institut de Physique du Globe. Fascicule spécial consacré aux expériences de La Courtine sur la Propagation des ondes aériennes. Patis, 1926.

$$
\text { NO. } 2965 \text {, VOL. I I } 8]
$$

x924. In each of the first two, about ten tons of melanite was spent, in each of the others, five tons. Observers did not receive sufficient warning in the last case, and M. Maurain's report is practically confined to the other three.

The great advantage of organisation is manifest throughout the report. When explosions have occurred by accident, the places at which they were heard have in many cases been mapped successfully, but accurate records of the time have been raré. With an experimental explosion the observers are ready to note the time to a second at which the sound reaches them. In many of the places from which Prof. Maurain received reports, the agreement between the observers was excellent. Perhaps the best example of precision is provided by the observations at Bordeaux on the first occasion. In the observatory and near by, four observers gave the time as I9 h. 44 m. $5 \mathrm{~s}$., two gave I9 h. $44 \mathrm{~m} .4 \mathrm{~s}$, , and one ig h. $44 \mathrm{~m} .3 \mathrm{~s}$.

Another advantage is that full information can be obtained as to the meteorological conditions. There were at least two soundings of the upper air in France on each of the three 'La Courtine' days, and the stratosphere was reached on each occasion. Special 
pilot balloon ascents gave the direction of the air currents in the lowest three or four kilometres.

In the discussion of the observations, Maurain distinguishes between normal and abnormal audibility ; for normal audibility the quotient of distance and time is approximately equal to the velocity of sound near the ground, whereas for abnormal audibility the quotient is considerably smaller. In each of the three La Courtine experiments there was a welldefined zone of silence separating zones of normal and abnormal audibility. The maps illustrating the last two experiments are comparatively simple and remarkably consistent. In each, the zone of normal audibility extends about roo km. N.E. from La Courtine (with the wind), but barely $25 \mathrm{~km}$. in the opposite direction. The zone of abnormal audibility occupies a quadrant to $S . W$., the minimum distance being about $160 \mathrm{~km}$.

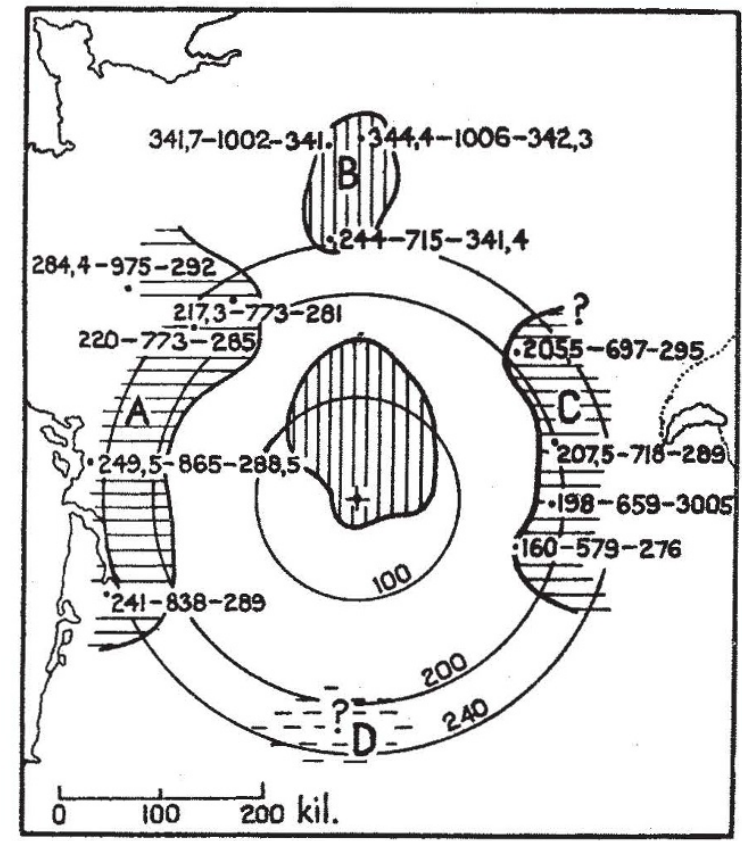

FIG. x. - The numbers against the dots representing reporting stations are :-The distance from La Courtine in kilometres, the time after the circles are not in the original.

Two or three small detached areas of audibility are also shown to the east and north. The map for May I5, which we reproduce (Fig. I), is of special interest on account of its remarkable symmetry. There were zones of abnormal audibility to east and west of the explosion. A detached region of normal audibility is also mapped in the neighbourhood of Paris, but it is to be noted that the observations in this area were instrumental. The records suggest waves of long period, beyond the range of the ear. With the favouring wind, the long waves travelled better than short ones through the lower atmosphere. As evidence for the favouring wind, it may be mentioned that the Upper Air Supplement of the Daily Weather Report shows that there was a current from the south crossing the English Channel at the cirrus level ; the velocity deduced from nephoscope observations was about roo miles per hour.

In a report of this kind the presentation of the observations in a convenient way is the main issue; it is to be regretted, however, that in the theoretical discussion the author has ignored details and adopted very rough approximations. Although he has been at pains to record the distribution of wind and temperature in the lower atmosphere, he boldly assumes that the sound rays in that region are straight. Moreover, he assumes that the stratosphere is uniform in temperature and composition up to $50 \mathrm{~km}$. above ground, and does not test alternatives. His conclusions are that the high temperature postulated by Lindemann and Dobson for the atmosphere at $60 \mathrm{~km}$. and above (say $300^{\circ} \mathrm{A}$.) is not high enough to account for the recurving of the sound rays, and that Von dem Borne's hypothesis of the hydrogen atmosphere must be invoked. He goes so far as to hazard the estimate of 92 per cent. of hydrogen in the constitution of the atmosphere at $116 \mathrm{~km}$., the height suggested for the apex of the path of the sounds heard at Bordeaux.

Fortunately, the observations provide us with a simple criterion by which such statements can be tested. Prof. Wiechert has reminded us recently that there is a close relation between the rate at which the intersection of a sound wave with the earth progresses and the velocity of sound at the apex of the trajectory. In the case of absence of wind and uniform stratification, these are equal. If there is a wind at the level of the apex, the component of the wind velocity in the direction of propagation of the sound must be allowed for. Now, in the La Courtine experiments there are three cases in which the radial velocity of the disturbance in the zone of abnormal audibility can be estimated.

In the first experiment there were well-supported observations to the north-west of La Courtine, at Chinon, and at Angers.

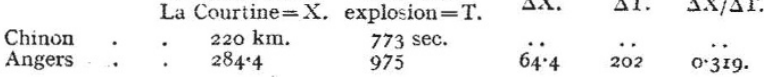

On May 23 there were observations at Angoulême, Rochefort, and Bordeaux, and as the straight line from La Courtine to Angoulême when produced bisects approximately the line from Rochefort to Bordeaux, we may take the average of the co-ordinates of those two stations for comparison.

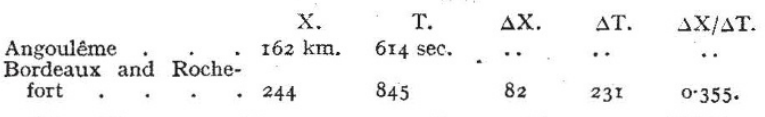

On May 25 there were observations at Vélines between La Courtine and Bordeaux.

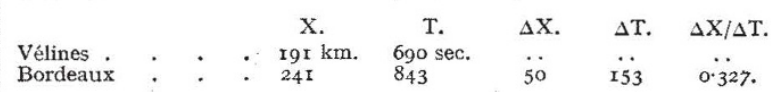

It will be seen that in each of these cases the sound travelled across the zone of abnormal audibility with a speed differing but little from the ordinary speed of propagation, which for the temperature $\mathrm{I} 7^{\circ} \mathrm{C}$. is about $34 \mathrm{I}$ metres per second. In each case the sound was travelling against a light surface wind and would be retarded thereby.

Two deductions may be made :

(I) In the outer part of the zone of abnormal audibility the wave fronts were nearly vertical, the rays nearly horizontal. 
(2) Unless the apexes of the sound rays were in a region of strong wind, they must have been at a level where the velocity of sound was about the same as at ground level.

Prof. Maurain's hypotheses are at variance with these deductions from the observations. He contemplates rays, the inclination of which at the ground is only $22^{\circ}$ from the vertical, and the velocity of sound at the apex of such sound rays is said to be 786 metres per second. It is clear that further discussion of the observations is called for.

In our diagnosis of the conditions, we start with the known facts with regard to the state of the atmosphere on May I5. As a good approximation we take the temperature of the surface air as $290^{\circ} \mathrm{A}$., the lapse rate of temperature $63^{\circ}$ per $\mathrm{km}$. up to $x 2 \mathrm{~km}$., and assume a uniform temperature $210^{\circ}$ from $\mathrm{I} 2 \mathrm{~km}$. upwards.

The region of uniform temperature may be supposed to extend to a height $\mathrm{H}_{2}$. Above $\mathrm{H}_{2}$, temperature is higher. It may be supposed that at the height $\mathrm{H}_{3}$, temperature is the same as on the ground, $290^{\circ} \mathrm{A}$., the inverted lapse rate being the same from $\mathrm{H}_{2}$ to $\mathrm{H}_{3}$ and
It will be seen that in each of these cases it is indicated that the region of high temperature begins at about $30 \mathrm{~km}$. above ground. The apex of the specified ray is between 40 and $50 \mathrm{~km}$. above ground, and the temperature there is in the neighbourhood of $300^{\circ} \mathrm{A}$.

Values of $\mathrm{H}_{2}$ and $\mathrm{H}_{3}$ having been determined, we can compute the values of $\mathrm{X}$ and $\mathrm{T}$ for rays of various inclinations. Thus, if $\mathrm{H}_{2}$ is 32 and $\mathrm{H}_{3}$ is $45^{\cdot 2}$, we obtain the following table: ${ }^{2}$

\begin{tabular}{|c|c|c|c|c|c|}
\hline$\psi_{0}$ & $x$. & $\mathrm{T}$. & $\Delta x$ & $\Delta \mathrm{T}$. & $\Delta X / \Delta T$ \\
\hline 0 & $247 \times 5$ & 853.7 & .. & & .. \\
\hline 5 & 234.4 & $8 \times 5.4$ & $13 \cdot 1$ & $3^{8 \cdot 3}$ & 0.342. \\
\hline ro & $225 \cdot 3$ & $789 \cdot 0$ & 9'I & $26 \cdot 4$ & 0.345 . \\
\hline 15 & $220 \cdot 3$ & 774.8 & 5.0 & $14 \cdot 2$ & 0.352. \\
\hline 20 & 219.8 & 773.3 & $\cdot 5$ & I.5 & 3 \\
\hline 25 & $224 \cdot 3$ & 785.6 & $-4 \cdot 5$ & $-12 \cdot 3$ & 0.370 \\
\hline
\end{tabular}

It will be seen that the range is a minimum for an inclination about $18^{\circ}$. The figures in the last column illustrate Wiechert's principle.

The course of the rays in this example is illustrated in Fig. 2. The figure shows how the rays which return to earth are distributed over a rather narrow zone. That the zone of abnormal audibility is actually wider in observed cases is no doubt to be explained

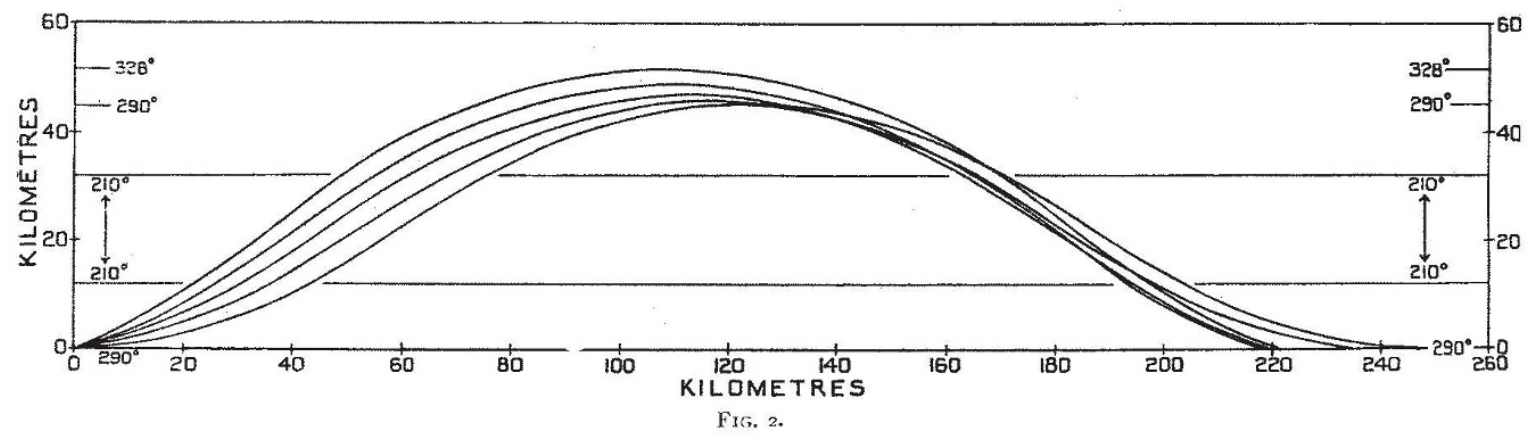

beyond. With these assumptions, wind being ignored, a sound ray consists of arcs of cycloids in the troposphere and the upper atmosphere and of straight lines in the stratosphere.

For a ray starting with a given inclination to the horizon, the range, etc., can be expressed as linear functions of $\mathrm{H}_{2}$ and $\mathrm{H}_{3}$. For example, for a ray starting with the inclination $\psi=15^{\circ}$, we have the formulæ :

Range in kilometres $=\mathrm{X}=\mathrm{I} 7 \cdot 8-5 \cdot 46 \mathrm{H}_{2}+8 \cdot 35 \mathrm{H}_{3}$.

Time of passage in seconds $=\mathrm{T}=36 \cdot 54-14 \cdot 55 \mathrm{H}_{2}+26 \cdot 64 \mathrm{H}_{3}$. Height of apex in kilometres $=\mathrm{Z}=\mathrm{I} \cdot 26 \mathrm{H}_{3}-0 \cdot 26 \mathrm{H}_{2}$.

The observations of audibility give values of $\mathrm{X}$ and $\mathrm{T}$ and, if the inclination of the sound ray is assumed, such formulæ can be used to determine $\mathrm{H}_{2}$ and $\mathrm{H}_{3}$.

Four examples are quoted in the following table:

$\begin{array}{rrrrllccc} & \mathrm{X} . & \mathrm{T} . & \psi & \mathrm{H}_{2} . & \mathrm{H}_{3} . & \mathrm{Z} . & \theta . & \mathrm{V} . \\ \mathrm{I} . & 220 & 773 & \mathrm{I} 5 & 32 & 45 & 48 \cdot 6 & 3 \mathrm{II} & \mathrm{O} \cdot 354 . \\ \text { 2. } & 220 & 773 & 5 & 33 & 44 & 44 \cdot \mathrm{I} & 292 & 0 \cdot 343 . \\ \text { 3. } & 284 & 975 & \mathrm{O} & 34 & 5 \mathrm{I} \cdot 5 & 5 \mathrm{I} \cdot 5 & 290 & 0 \cdot 34 \mathrm{I} . \\ \text { 4. } & \mathrm{I} 60 & 579 & 20 & 30 & 37 & 40 \cdot 7 & 328 & 0 \cdot 363 .\end{array}$

$\psi=$ initial inclination of ray; $\theta=$ temperature at height $Z ; V=$ correspond$\begin{aligned} & \psi=\text { initial inclination } \\ & \text { ing velocity } \mathrm{km} . / \mathrm{sec} .\end{aligned}$

In the first two, the values of $\mathrm{X}$ and $\mathrm{T}$ are those appropriate for Chinon on May $x_{5}$; the alternative values $15^{\circ}$ and $5^{\circ}$ are assumed for the inclination.

In the third example, the figures for Angers are used, this being a case of a very long range, and in the fourth example, the figures for Unieux are selected to illustrate a very short range.

NO. 2965 , VOL. I I 8 ] by the complication introduced by wind. The computation of the exact forms of rays with the influences of wind and temperature both taken into account is very cumbersome. To discover a hypothetical distribution of both elements consistent with all the reported observations would therefore require much laborious arithmetic. It is to be hoped that some one will carry this through. It is not likely, however, that the general result, that the observations imply a region of high velocity and high temperature between 30 and $50 \mathrm{~km}$. above ground, will be modified. That this was probably the interpretation of the La Courtine observations was noticed when the preliminary account was published (F. J. W. Whipple, Meteorological Magazine, 1925, p. x6). Wiechert has come to the same conclusion as the result of the study of all the available evidence with regard to abnormal audibility (Met. Zeitschrift, March r926, p. 90).

The existence of high temperatures at great heights was deduced by Lindemann and Dobson from the evidence provided by observations of meteors (Royal Soc. Proc. A, vol. Io2, 1922, pp. 411-437). That this hypothesis would explain the 'abnormal' audibility of explosions was seen at once. There is, however, an apparent discrepancy. Lindemann and Dobson considered that the stratosphere with its uniform temperature might be regarded as reaching nearly to

2 The figures quoted for $15^{\circ}$ elevation do not tally precise y with the formulæ for $\mathrm{X}$ and $\mathrm{T}$ in which the coefficients have been rounded. 
$60 \mathrm{~km}$., and credited the higher temperature to the region above that level. The discussion of audibility brings the transition down to $30 \mathrm{~km}$. It seems, however, that the meteor observations are not inconsistent with this modification of the hypothesis.

In Fig. 3A, which is reproduced from part of Fig. 3 of Lindemann and Dobson's paper, the density of the air at different levels is shown by crosses and dots. Each cross shows the density computed for the point of appearance of a meteor, each dot that for a point of disappearance. The curve shows the density calculated on the assumption of a uniform temperature $220^{\circ}$ at all levels above $12 \mathrm{~km}$. The curve runs from $220^{\circ}$ to $300^{\circ}$ occurs between $30 \mathrm{~km}$. and $40 \mathrm{~km}$. The fit is now a little better. Finally, in Fig. 3D, I have made the rise of temperature begin at $30 \mathrm{~km}$. and assumed a regular increase up to $50 \mathrm{~km}$. At that level and beyond, the temperature is $380^{\circ}$. The assumptions are now in reasonable agreement with the observations.

It is difficult to believe that the atmosphere at $60 \mathrm{~km}$. is really at a temperature above the normal boiling-point of water. That seems, however, to be the logical conclusion from the theory of Lindemann and Dobson. For our present purpose the essential point is that the meteor observations do not
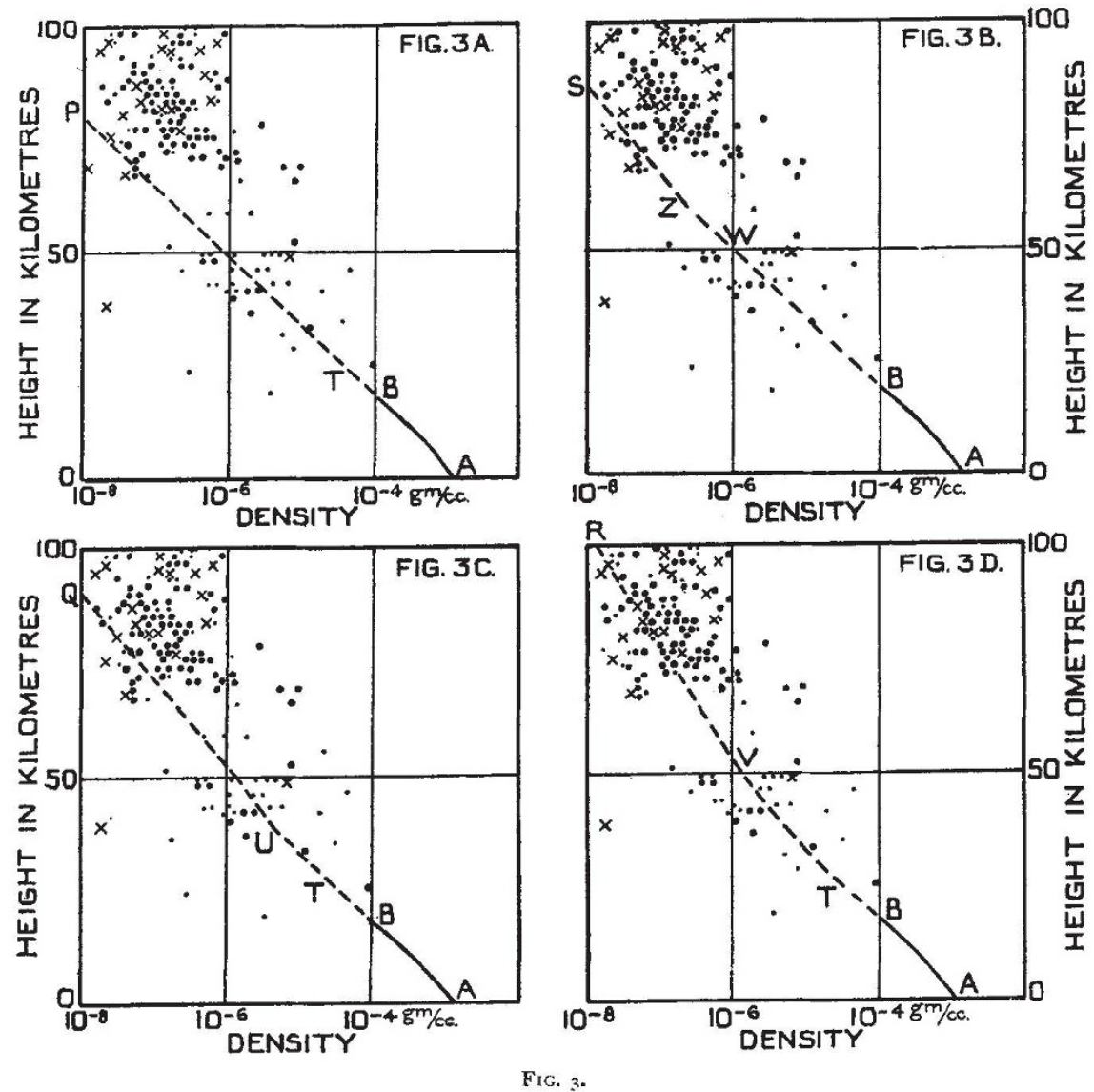

fairly through the points representing meteor observations below $60 \mathrm{~km}$. As Lindemann and Dobson point out, above $60 \mathrm{~km}$. the meteor observations "all indicate densities very much greater than those calculated on the assumption of a uniform air temperature of $220^{\circ} \mathrm{A}$., but consistent with a considerably higher temperature." They state that the rate of change of density with height shows that the temperature is probably about $300^{\circ} \mathrm{A}$., but how this estimate is reached is not clear. I have shown in Fig. $3^{\mathrm{B}}$ the curve which represents the relation between density and height on the assumption that temperature is $220^{\circ}$ from $I 2 \mathrm{~km}$. to $50 \mathrm{~km}$., that there is a uniform gradient to $60 \mathrm{~km}$., and that temperature above $60 \mathrm{~km}$. is $300^{\circ}$. It will be seen that the curve does not represent the meteor observations at all well. In Fig. $3 \mathrm{C}$ I have adopted the hypothesis that the transition

conflict with the hypothesis suggested by the phenomenon of abnormal audibility, i.e. that temperature is about $220^{\circ}$ up to $30 \mathrm{~km}$., about $300^{\circ}$ at $40 \mathrm{~km}$., and possibly higher above that level.

The apparent inconsistency between the theory of Lindemann and Dobson and their conclusions was pointed out recently by C. M. Sparrow, who interprets their diagram as implying a temperature of $480^{\circ}$ (Astrophysical Journal, 63, March 1926, pp. 90-110). Sparrow does not accept the theory, and puts forward one of his own, which does not require high temperatures at all. The reply of Lindemann and Dobson to Sparrow's arguments has not yet appeared.

Realisation of the probability that the transition from the uniform temperatures of the stratosphere to much higher temperatures begins at the comparatively modest height of $30 \mathrm{~km}$. makes it desirable to extend 
the range of soundings by free balloons to that height, and beyond. By the proper choice of balloons that should be possible.

Another line of attack is also open. We are familiar with the fact that, during the War, gunfire was heard regularly at distances exceeding roo miles. Why should not similar observations be made systematically in peace time? I should like to inquire whether gun practice at Portland is heard in South Wales. If there is any quiet spot in that region where the sounds are heard frequently, observations should be timed and, with a little organisation, valuable information would be obtained. The advantage of frequent observations of this kind as compared with the occasional 'big bang' 'is obvious.

Since this article was written I have had an opportunity of testing the possibility of timing the passage of the sound of gunfire. Listening at Grantham on June 28 for the discharge of guns at Shoeburyness, II 5 miles away, I found that the time of passage increased gradually from IO $\frac{3}{4}$ to $I I \frac{1}{4}$ minutes and then began to decrease. Details have been published in the Meteorological Magazine for August.

\section{Obituary.}

\section{DR. J. F. HALl-EDWARDS.}

$\mathrm{W}^{\mathrm{s}}$ $E$ regret to record the death on August I5, at the age of sixty-seven years, after many years of suffering due to extensive X-ray injuries, of Dr. J. F. Hall-Edwards. He was educated at King Edward's School and at Queen's College, Birmingham, and after qualifying in medicine he went into practice. Soon after the discovery of X-rays, Dr. Hall-Edwards took up their application in medical work and was one of the earliest authors in radiography. He served in the South African War as surgical expert in X-ray work to the Imperial Yeomanry Hospitals at Deelfontein and Pretoria, receiving the Queen's medal with four clasps. In spite of disabilities which might well have deterred him from any further executive work, he applied for and received a commission as temporary Major in the R.A.M.C. at the outbreak of war in I9I4, and served in a radiological capacity to such effect that official recognition of his services was made on two occasions. He was an honorary member of the Röntgen Society and the author of several original papers in the journals of this Society and of the
Electro-therapeutic Section of the Royal Society of Medicine.

Dr. Hall-Edwards made a great fight for many years against the insidious damage which he had suffered when using $\mathrm{X}$-rays in his medical work. Like other pioneers he suffered because protective methods were unknown. His services in the public cause which so unhappily affected him, were recognised by the award of a Civil List pension in 1908, and later, in 1922, he received the Carnegie Hero Trust Medallion with an annuity.

S. Russ.

WE regret to announce the following deaths :-

Dr. Charles W. Eliot, for forty years president, and since I909, president emeritus of Harvard University, who was largely responsible for raising Harvard to its present high position among the universities of the world, on August 22, aged ninety-two years.

Dr. D. E. Flinn, formerly medical inspector of the Local Government Board, Ireland, editor of the Health Record and author of works on public health and hygiene in Ireland, on August I8, aged seventysix years.

\section{News and Views.}

Sir ARThur Evans's paper on "The Shaft Graves of Mycenæe and their Contents in Relation to the Beehive Tombs," which was read before the Anthropological Section of the British Association at Oxford, was something in the nature of a bomb-shell, of which the effects will be far-reaching. The relation of the great beehive tombs at Mycenæ, which were found empty of their sepulchral contents, to the shaftgraves, so rich in sepulchral relics, found by Schlieman within an extension of the Acropolis wall, has always been a puzzle to archæologists. Sir Arthur's paper revived a theory, first put forward by Prof. Gardner and arrived at independently by himself, that at a time of danger the royal burials had been transferred from the mausolea outside the walls to a site which could be included within the enceinte. This theory has not found favour among archæologists, and the view generally held is that the two classes of tombs correspond to earlier and later dynasties at Mycenæ. Mr. Wace recently has carried the matter further and suggested that the two finest shaftgraves, the "Treasury of Atreus" and the "Tomb of
Clytemnestra," belong to the latest groups, making them contemporary with a time when the Palace of Knossos was in ruins and the civilisation of Crete on the downward path. Sir Arthur Evans's latest discoveries render this theory untenable. He has found decorative sculptures, not later in date than the end of the Third Middle Minoan period and in vogue about I 700 B.C., which run parallel with those of the façade of the "Atreus" tomb. Vases characteristic of the same epoch were found in the "Tomb of Clytemnestra." $\mathrm{He}$ was able to demonstrate archæologically that the finest of the beehive tombs belong to the same date as the earliest elements in the shaft graves, and that both are equally Minoan. On this view their culture, with the exception of certain intrusive barbaric elements, can no longer be regarded as a 'mainland' culture and, as Sir Arthur pointed out, the term 'Helladic' as applied to it becomes a misnomer.

Sir Frederick Keeble, Sherardian professor of botany in the University of Oxford, has accepted an

$$
\text { No. } 2965 \text {, VOL. I I } 8]
$$

